\title{
Diel Feeding Rhythm and Grazing Selectivity of Small-Sized Copepods in a Subtropical Embayment, the Northern South China Sea
}

\author{
Xuejia He ${ }^{1 *}$, Ziyu Wang ${ }^{1}$, Ziqing Bai ${ }^{1}$, Liuyu Han ${ }^{2}$ and Mianrun Chen ${ }^{3 *}$ \\ ${ }^{1}$ Research Center of Harmful Algae and Marine Biology, Key Laboratory of Eutrophication and Red Tide Prevention \\ of Guangdong Higher Education Institutes, Jinan University, Guangzhou, China, ${ }^{2}$ Haikou Marine Environment Monitoring \\ Station of State Oceanic Administration, Haikou, China, ${ }^{3}$ South China Sea Institute of Planning and Environmental Research, \\ SOA, Guangzhou, China
}

OPEN ACCESS

Edited by:

Li-Chun Tseng,

National Taiwan Ocean University,

Taiwan

Reviewed by:

Marilia Bueno,

State University of Campinas, Brazi

Edson A. Vieira,

Federal University of Rio Grande do

Norte, Brazil

Yen-Ju Pan

National Taiwan Ocean University,

Taiwan

${ }^{*}$ Correspondence:

Xuejia $\mathrm{He}$

thexuejia@jnu.edu.cn

Mianrun Chen

cmrandy@scs.mnr.gov.cn

Specialty section

This article was submitted to

Marine Biology,

a section of the journal

Frontiers in Marine Science

Received: 26 January 2021

Accepted: 03 May 2021

Published: 09 June 2021

Citation:

He X, Wang Z, Bai Z, Han L and Chen $M$ (2021) Diel Feeding Rhythm and Grazing Selectivity of Small-Sized

Copepods in a Subtropical

Embayment, the Northern South

China Sea. Front. Mar. Sci. 8:658664.

doi: 10.3389/fmars.2021.658664
Small marine copepods are key components of the pelagic food webs in Chinese coastal waters, but very few studies have addressed their trophodynamics, with even fewer studies addressing their diel feeding rhythms. In this study, the diel feeding rhythm and grazing selectivity of the copepod assemblage in Daya Bay during September 30 to October 2, 2014, were studied based on gut pigment analysis. Small copepods (body length $<1.5 \mathrm{~mm}$ ) including Paracalanus parvus, Temora turbinata, Acrocalanus gibber, Temora stylifera, Euterpe acutifrons, and Acrocalanus gracilis, accounted for 73.9$100 \%$ of the total copepod abundance. The copepod assemblage generally exhibited a diurnal feeding pattern, characterized by a higher gut pigment content and ingestion rate during the daytime, consistent with variation in the ambient $\mathrm{Chl} \alpha$ concentration. Fifty-five percent of the phytoplankton standing stock per day was consumed by the copepod assemblage, wherein diatoms, prymnesiophytes, and cyanobacteria were the main prey items with average contributions of $19.4-32.9 \%$ to the gut pigment contents. The copepod assemblage showed a strong feeding preference for prymnesiophytes, a weak feeding preference for diatoms, and avoidance of cyanobacteria. These results suggest a strong top-down control on phytoplankton community, especially on small groups from small copepods in the Daya Bay ecosystem.

Keywords: Daya Bay, small copepod, diel feeding rhythm, grazing selectivity, gut pigment, diel vertical migration, grazing pressure

\section{INTRODUCTION}

Copepods are the predominant mesozooplankton in marine pelagic system (Longhurst, 1985). Small copepods $(\sim 1 \mathrm{~mm}$ in length) including adults and juveniles of calanoid genera such as Paracalanus, Clausocalanus, and Acartia and non-calanoid species and it has been increasingly recognized that they, accounting for up to $90 \%$ of copepod abundance, represent an extremely important constitute of copepod community in coastal and estuarine waters (Hopcroft et al., 1998; Turner, 2004; Liu et al., 2013; Han, 2015; Cheng, 2019). Their abundance and biomass, however, have historically been significantly underestimated in the copepod community in early studies, owing to the usage of coarse mesh nets $(\sim 500 \mu \mathrm{m})$. Consequently, although small copepods are good food items for larval or juvenile pelagic fishes, especially small fishes (Tipton and Bell, 1988; Castonguay et al., 2008; Costalago et al., 2012), their roles in fisheries and carbon 
cycling were greatly underrated as well (Wang et al., 2002). Furthermore, small copepods usually selectively graze on picoand nano-phytoplankton and relatively may consume more of smaller sized phytoplankton relative to large copepods in many systems (Zervoudaki et al., 2007; Isari and Saiz, 2011), which means that energy and material may be transferred from pico- and nanophytoplankton through small copepods to higher trophic level more efficiently under the circumstance that a miniaturization trend has been occurring in phytoplankton community in many marine systems (Shen, 2001; Wei, 2003; Chen et al., 2010; Wu et al., 2017; Chiba, 2019).

The diel feeding rhythm, as one of important aspects of trophodynamics of marine pelagic copepods, has long attracted extensive attention (Fuller, 1937; Harding et al., 1986; Olivares et al., 2020). Most of copepods show higher nocturnal feeding (Peterson et al., 1990). Small copepod, like genus Acartia, usually showed strong nocturnal feeding tendency (Durbin et al., 1990; Wlodarzyk et al., 1992; Kouassi et al., 2001; Kibirige and Perisinotto, 2003; Pagano et al., 2006), while another genus Paracalanus have a weak one (Tiselius, 1988; Peterson et al., 1990; Saito and Taguchi, 1996). In some occasion, species belonging to these two genera show reverse tendency (Tang et al., 1994; Lee et al., 2012). Furthermore, diurnal feeding rhythms are observed in a few copepods (Kiørboe et al., 1985; Roman et al., 1988). The diel feeding rhythm is generally proposed to be dependent on the diel vertical migration of marine copepods (Champalbert et al., 2003), but non-migratory species also show diel feeding rhythms (Hayward, 1980; Tang et al., 1994). More convincingly, the diel feeding rhythm is primarily modulated by the endogenic factors of copepods (Durbin et al., 1990), as well as food environments and the risk of predation or a combination of these (Durbin et al., 1990; Wu et al., 2010; Olivares et al., 2020), as was supported by many previous studies. As such, it is expected that the diel feeding rhythm of a copepod assemblage will be more complicated with entangled aforementioned factors and the variable community composition.

Daya Bay is among the coastal ecosystems in China, where ecological environments have changed greatly in recent years because of anthropogenic activities (Qiu et al., 2005; Liu et al., 2012; Wu et al., 2016) and the miniaturization of phytoplankton is prominent (Qiu et al., 2005). Small copepods, including Paracalanus parvus, Paracalanus crassirostris, and Oithona spp., occur perennially in western Daya Bay as the predominant mesozooplankton species according to the latest investigations with $169 \mu \mathrm{m}$-mesh nets (Liu et al., 2013; Han, 2015; Cheng, 2019). Studying the trophodynamics of small copepods in this area is important for clarifying the trophic interactions between small copepods and phytoplankton, but unfortunately, no such studies have been performed.

This study, by means of gut pigment analysis technique, aims (i) to explore the potential diel feeding rhythm and test whether the environmental conditions and diel vertical migration modulate the pattern, (ii) to evaluate the grazing pressure of the small copepod assemblage on different phytoplankton classes to test the hypothesis that small copepods exert strong grazing pressure on the pico- and nano-phytoplankton in Daya Bay.

\section{MATERIALS AND METHODS}

\section{Study Area}

Daya Bay, located in the northern South China Sea (NSCS), is a typical subtropical drowned-valley bay. This semi-enclosed shallow embayment covers $650 \mathrm{~km}^{2}$ with depths of 5-15 m. In the past three decades, this area has been severely influenced by anthropogenic activities, including aquaculture and the operation of nuclear power plants since 1993, and the eutrophication level has been classified as medium.

\section{Sampling}

Sampling was conducted for $48 \mathrm{~h}$ with a 6 -h frequency at the study site, which was located nearshore in the western part of Daya Bay $\left(22^{\circ} 33^{\prime} 48.6^{\prime \prime} \mathrm{N}, 114^{\circ} 35^{\prime} 0.6^{\prime \prime} \mathrm{E}\right.$, Figure 1), between sunset on September 30 and noon on October 2. Vertical profiles of water temperature and salinity were measured with YSI Pro Plus (YSI Incorporated, Yellow Springs, OH, United States). Copepods were collected from each of the upper layer $(0-3 \mathrm{~m})$, middle layer $(3-6 \mathrm{~m})$, and bottom layer $(6-10 \mathrm{~m})$ by vertical tows for three times corresponding to three different aims, with a closing conical net $(31.6 \mathrm{~cm}$ diameter, $169-\mu \mathrm{m}$ mesh size), which can be closed at a specific depth. Copepods from the first tow were preserved in 5\% formaldehyde for later identification and enumeration under a stereomicroscope. Copepods from the second tow were rinsed and collected on GF/F filters and stored in liquid nitrogen for biomass determination. Upon retrieval of the third tow, the cod end containing the animals was immersed into a beaker containing soda water for $2 \mathrm{~min}$. Then the animals were gently filtered, rinsed with FSW, and frozen with dry ice. All samplings were in duplicate. Within $24 \mathrm{~h}$ of sample collection, zooplankton samples were thawed.

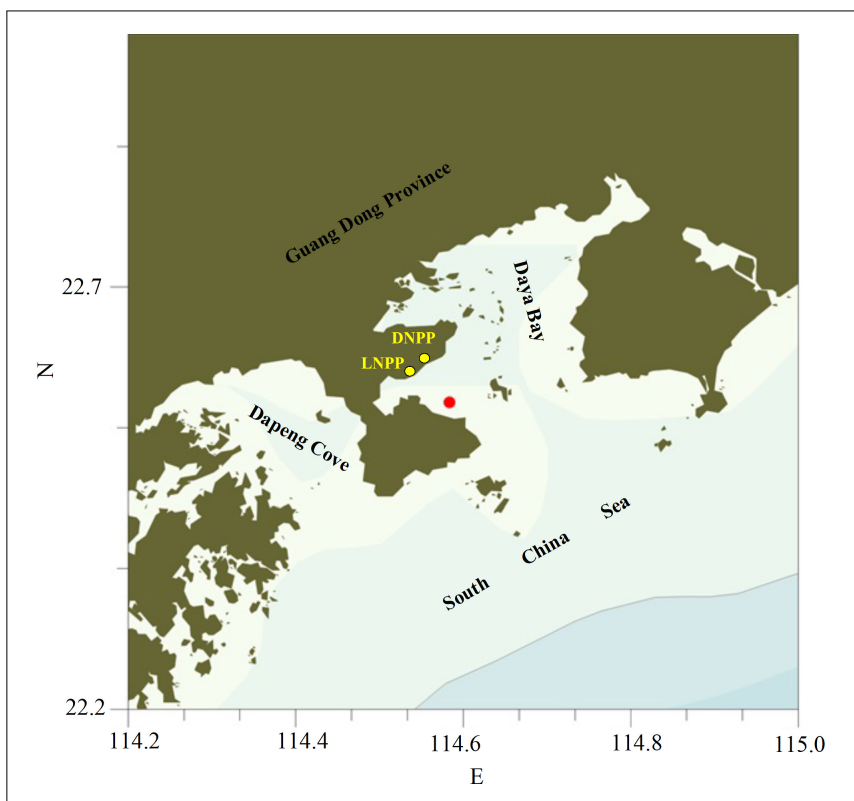

FIGURE 1 | Map of the sampling station in Daya Bay (DNPP, Daya Bay Nuclear Power Plant; LNPP, Lingao Nuclear Power Plant). 
Then, above an ice-containing bowl and under a stereoscopic microscope, copepods were picked up under dim light and moved into 1.5-mL PE tubes. Finally, the copepods were freeze-dried for later gut pigment extraction and measurement.

Five liters of seawater were collected from each layer with a van Dorn water sampler, and zooplankton were immediately removed by passing seawater through $200-\mu \mathrm{m}$ sieves. Then, the samples were returned to the laboratory immediately. In the laboratory, phytoplankton were concentrated on Whatman $\mathrm{GF} / \mathrm{F}$ filters in the dim light, which were combusted at $480^{\circ} \mathrm{C}$ for $2 \mathrm{~h}$ beforehand in a muffle furnace. Under the microscope, microzooplankton were removed from filters with needles quickly and the filters were then preserved immediately in liquid nitrogen for later pigment extraction and measurement. These filtrations were conducted under dim light to avoid pigment degradation.

Copepod taxa were identified to the species level under a stereomicroscope. Dominance was measured with the BergerParker index according to Magurran (1988). The species with a dominance value $\geq 0.02$ were considered dominant species.

\section{Pigment Measurement}

The filters holding phytoplankton cells were immersed in $3 \mathrm{~mL}$ of $95 \%$ methanol, while freeze-dried copepods were transferred into glass tubes containing $3 \mathrm{~mL}$ of $95 \%$ methanol. These samples were sonicated for $8 \mathrm{~min}$ and then stored at $4^{\circ} \mathrm{C}$ for $24 \mathrm{~h}$ in darkness for pigment extraction. An internal standard, $\beta$-apo$8^{\prime}$-carotenol (trans) (Sigma-Aldrich, United States), was added at the very beginning to correct the volume change during sample processing.

An aliquot of $100 \mu \mathrm{L}$ of pigment extract was injected into a reversed-phase Eclipse XDB-C8 column $(150 \times 4.6 \mathrm{~mm}$, $3.5 \mu \mathrm{m}$, Agilent). An Agilent HP 1200 Series HPLC system consisting of an autosampler, a quaternary pump equipped with a diode array detector and a fluorescence detector was used to quantify phytoplankton pigment and copepod gut pigment concentrations.

Pigment separation followed a method adapted from Zapata et al. (2000). It consisted of a binary linear gradient programmed as follows (min, percentage of solvent $\mathrm{A}$, percentage of solvent B): $(0,0,100)(22,40,60)(6,95$, 5) $(11,0,100)$. Solvent A consisted of 20:20:60 (v/v/v) methanol:acetone:acetonitrile solution, and solvent B consisted of 50:25:25 (v/v/v) methanol:acetonitrile:pyridine solution. The pyridine solution was adjusted to a $\mathrm{pH}$ of 5 with acetic acid.

Identification and calibration of pigments were performed with commercial standards, namely, chlorophylls $\alpha, b, c_{2}$, and $c_{3}$ and $\beta$-carotene, peridinin, fucoxanthin, neoxanthin, violaxanthin, diadinoxanthin, alloxanthin, 19'-but-fucoxanthin, prasinoxanthin, 19'-hex-fucoxanthin, diatoxanthin, zeaxanthin, lutein, and canthaxanthin (DHI Water and Environment, Inc.). Standards of breakdown products of chlorophylls $\alpha$ and $b$ were prepared following the procedures given by Brotas and Plante-Cuny (1998) and Plante-Cuny et al. (1993). Standard solutions were prepared by dissolving all pigments in $100 \%$ methanol (pheophytin a) and $100 \%$ ethanol, and the concentrations were adjusted to $2-300 \mathrm{ng} \mathrm{mL}^{-1}$.
The contributions of seven algal classes, namely, Bacillariophyta, Cyanophyceae, Chlorophyta, Prymnesiophyceae, Cryptophyta, Dinoflagellata, and Pelagophyceae, to total chlorophyll $\alpha$ (Chl $\alpha$ hereafter) or total gut chl $\alpha$ were estimated with the matrix factorization program CHEMTAX 1.95 (Mackey et al., 1997). For the analysis, the initial marker pigment:Chl $\alpha$ ratios for various algal taxa extracted from previous studies in adjacent sea areas by Wang et al. (1999); Chen et al. (2006), and He and Peng (2012) were used.

\section{Ingestion Rate and Selectivity Index Calculation}

Chl $\alpha$ and phaeopigment (mainly pheophorbide a) data obtained from HPLC analysis were further used to calculate the ingestion rates of the copepods. Phaeopigment concentrations were converted into $\mathrm{Chl} \alpha$ equivalents at a ratio of 1.51 (Dagg and Wyman, 1983). The average body length of copepods in each sample was estimated with the length-weight equation constructed for copepods by Watkins et al. (2011) based on the dry weight obtained in this study, and the calculation revealed that the average length was $1 \sim 2 \mathrm{~mm}$ or $<1 \mathrm{~mm}$ for different layers. Correspondingly, a gut evacuation rate of 0.028 or $0.022 \mathrm{~min}^{-1}$ was applied for ingestion rate calculations for 1 2-mm- and < 1-mm-long copepods using the equation in Tseng et al. (2009).

Group specific grazing pressure were firstly calculated combining specific ingestion rate and standing stock of each phytoplankton group for each layer during each period of $6 \mathrm{~h}$, and, by integration through time and different layers, the average grazing pressure was obtained for each phytoplankton group. Finally, the average grazing pressure for total phytoplankton community was calculated by dividing the total ingestion rate with integrated Chl $\alpha$ of the water column.

Grazing selectivity was assessed in two ways:

(1) Using the chi-square $\left(\chi^{2}\right)$ test to compare the frequency distribution of groups of phytoplankton in the diet and the frequency distribution in the environment (Cowles, 1979; Kleppel et al., 1996) and

(2) Comparing the distributions of selectivity indices between groups of phytoplankton with Kolmogorov-Smirnov and Mann-Whitney tests. The grazing selectivity index E was calculated following Ivlev (1961) based on the equation $\mathrm{E}=\left(\mathrm{r}_{\mathrm{i}}-\mathrm{p}_{\mathrm{i}}\right) /\left(\mathrm{r}_{\mathrm{i}}+\mathrm{p}_{\mathrm{i}}\right)$, where $\mathrm{r}_{\mathrm{i}}$ is the relative proportion of one phytoplankton phylum in the gut $\mathrm{Chl} \alpha$ of copepods and $\mathrm{p}_{\mathrm{i}}$ is the relative proportion of the same phytoplankton phylum in the ambient $\mathrm{Chl} \alpha$. In detail, $-0.25<\mathrm{E}<+0.25$ indicates non-selective feeding, $\mathrm{E}>+0.25$ indicates a preference, and $\mathrm{E}<-0.25$ indicates avoidance of particular prey items (Cotonnec et al., 2001).

\section{Statistical Analysis}

Two-way ANOVA was used to analyze differences in hydrogical parameters, copepod biomass, and gut $\mathrm{Chl} \alpha$ content between depths and time (daytime: 12:00 and 18:00; nighttime: 24:00 and 6:00) and the interactive effects of these two factors as 
well, whereas one-way ANOVA was performed to compare the contribution of different phytoplankton groups to the total phytoplankton biomass or to the gut $\mathrm{Chl} \alpha$ content, and to clarify the variance in ingestion rate of copepod with time, all followed by a Tukey post hoc test. The linear correlation between ingestion rate or gut pigment content and ambient food concentration was analyzed with Pearson analysis. KolmogorovSmirnov and Mann-Whitney tests were applied to analyze the similarities in grazing selectivity of copepods on phytoplankton groups. Statistical significance was set at $<0.05$.

\section{RESULTS}

\section{Environmental Parameters}

The average water temperature decreased significantly with increasing depth during the daytime (12:00 and 18:00) and nighttime (24:00 and 6:00) (both $p<0.001$, two-way ANOVA, Tables 1, 2). Salinity increased slightly but significantly with increasing depth $(p<0.001$, two-way ANOVA, Table 1). Water temperature was higher during the daytime than at night $(p=0.01)$, while there was an interaction between the effects of layer and time on salinity ( $p=0.002$, two-way ANOVA, Tables 1, 2).

The Chl $\alpha$ concentration, which ranged from 0.51 to $3.85 \mu \mathrm{g}$ $\mathrm{L}^{-1}$, varied significantly with time ( $p=0.036$, two-way ANOVA), and also showed a significant difference between daytime and nighttime (average: $2.00 \pm 1.27$ vs. $0.80 \pm 0.27 \mu \mathrm{g} \mathrm{L}^{-1}, p=0.017$ ) but no difference between layers ( $p=0.806$, two-way ANOVA, Table 2 and Figure 2). The Chl $\alpha$ concentration in all the layers showed a trend of increasing beginning at dawn, peaking at noon and then decreasing at sunset. Interestingly, the $\mathrm{Chl} \alpha$ climax occurred at noon on October 2 in all layers (3.53-3.85 $\mu \mathrm{g} \mathrm{L}^{-1}$, Figure 2; $p=0.047$, two-way ANOVA, Table 2).

\section{Phytoplankton Community Structure}

Based on CHEMTAX processing of diagnostic pigments, diatoms was the dominant phytoplankton group with average contribution of $30.2 \%$ and a wide range of contributions of $0.1-52.9 \%$ (all $p \leq 0.016$, one-way ANOVA; Figure 3), followed by cyanobacteria, cryptophytes and chlorophytes, which accounted for an average of 21.1, 18.2, and $10.7 \%$ to the total $\mathrm{Chl} \alpha$, respectively (all $p \leq 0.05$, one-way ANOVA; Figure 3). Prymnesiophytes, dinoflagellates and pelagophytes were minor contributors to phytoplankton biomass (4.1-4.7\% of the total Chl $\alpha$; all $p \leq 0.05$, one-way ANOVA; Figure 3).
TABLE 2 | Two-way ANOVA testing for difference in environmental parameters between layers (upper, middle, and bottom layers) and time (day or night).

\begin{tabular}{|c|c|c|c|c|c|c|}
\hline Parameter & Source & ss & df & MS & $F$ & $P$ \\
\hline \multirow[t]{5}{*}{ Temperature } & Layer & 4.516 & 2 & 2.258 & 16.410 & $<0.001$ \\
\hline & Time & 1.181 & 1 & 1.181 & 8.586 & 0.010 \\
\hline & Layer $\times$ Time & 0.107 & 2 & 0.053 & 0.388 & 0.685 \\
\hline & Error & 2.064 & 18 & 0.138 & & \\
\hline & Total & 7.969 & 23 & & & \\
\hline \multirow[t]{5}{*}{ Salinity } & Layer & 0.434 & 2 & 0.217 & 51.507 & $<0.001$ \\
\hline & Time & 0.000 & 1 & 0.000 & 0.098 & 0.759 \\
\hline & Layer $\times$ Time & 0.081 & 2 & 0.040 & 9.611 & 0.002 \\
\hline & Error & 0.063 & 18 & 0.004 & & \\
\hline & Total & 0.577 & 23 & & & \\
\hline \multirow[t]{5}{*}{ Chl $\alpha$} & Layer & 0.375 & 2 & 0.188 & 0.219 & 0.806 \\
\hline & Time & 5.907 & 1 & 5.907 & 6.887 & 0.017 \\
\hline & Layer $\times$ Time & 0.433 & 2 & 0.216 & 0.252 & 0.780 \\
\hline & Error & 15.437 & 18 & 0.858 & & \\
\hline & Total & 22.152 & 23 & & & \\
\hline \multirow[t]{5}{*}{ Copepod dry weight } & Layer & 4321.501 & 2 & 2160.750 & 2.897 & 0.081 \\
\hline & Time & 244.505 & 1 & 244.505 & 0.328 & 0.574 \\
\hline & Layer $\times$ Time & 388.341 & 2 & 194.171 & 0.260 & 0.774 \\
\hline & Error & 13426.193 & 18 & 745.900 & & \\
\hline & Total & 18380.541 & 23 & & & \\
\hline
\end{tabular}

Cyanobacteria shared the same diel variation pattern with the total Chl $\alpha$ in all layers (Figure 3), while dinoflagellates, prymnesiophytes and cryptophytes occasionally showed such a pattern in one or two layers.

\section{Vertical Distribution and Community Structure of Zooplankton}

Copepod biomass varied from 73.3 to $179.3,49.9$ to 117.1 , and 58.6 to $116.4 \mathrm{mg} \mathrm{m}^{-3}$ in the upper, middle, and bottom layers, respectively, during the 48-h study (Figure 4). Mean biomass did not differ among the layers ( $p=0.081$, two-way ANOVA, Figure 4 and Table 2).

The total copepod biomass showed subtle diel vertical distributions in different layers (Figure 4). In the upper layer, copepod biomasses were higher during the nighttime than during the daytime, with the lowest values at noon; this pattern was similar to but more even than that observed in the bottom layer. A converse pattern was found in the middle layer, except during the daytime on the last day. However, these trends were not statistically significant ( $p>0.05$, one-way ANOVA, Figure 4$)$.

TABLE 1 | Depth-averaged values of seawater temperature $\left(T,{ }^{\circ} \mathrm{C}\right)$, Salinity $(\mathrm{S}, \mathrm{psu})$, and $\mathrm{Chl} \alpha$ concentration $\left(\mu \mathrm{g} \mathrm{L}^{-1}\right)$ at the sampling station in Daya Bay during September 30 to October 2, 2014.

\begin{tabular}{|c|c|c|c|c|c|c|}
\hline & \multicolumn{3}{|c|}{ Day } & \multicolumn{3}{|c|}{ Night } \\
\hline Upper layer & $29.1 \pm 0.4$ & $31.0 \pm 0.1$ & $1.9 \pm 1.1$ & $28.5 \pm 0.6$ & $30.9 \pm 0.1$ & $0.8 \pm 0.3$ \\
\hline Middle layer & $28.5 \pm 0.1$ & $31.2 \pm 0.0$ & $1.8 \pm 1.3$ & $28.0 \pm 0.4$ & $31.1 \pm 0.1$ & $1.1 \pm 0.7$ \\
\hline Bottom layer & $27.9 \pm 0.1$ & $31.2 \pm 0.0$ & $2.0 \pm 1.3$ & $27.6 \pm 0.2$ & $31.4 \pm 0.0$ & $1.1 \pm 0.3$ \\
\hline
\end{tabular}




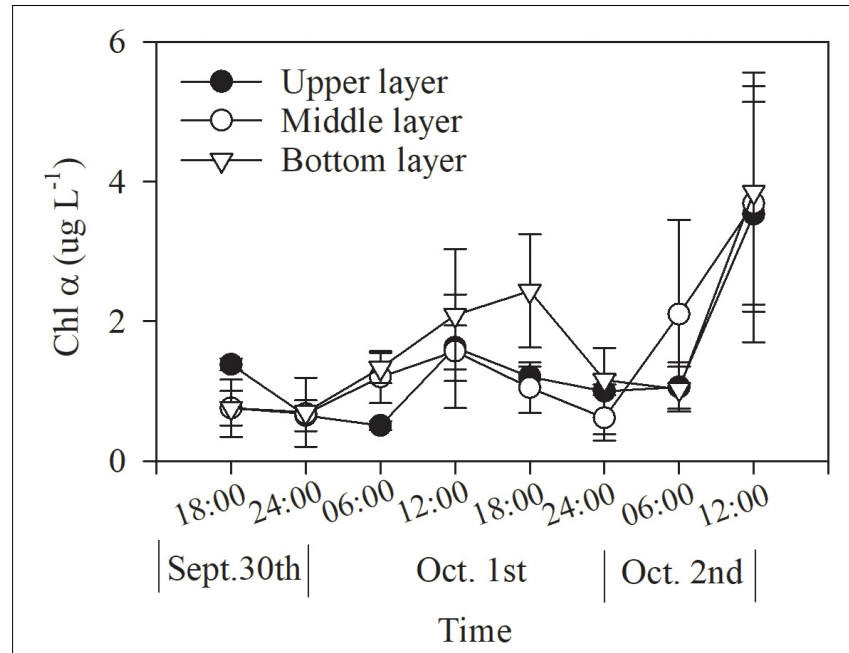

FIGURE 2 | Dial variation in Chl $\alpha$ concentration in Daya Bay during September 30 to October 2, 2014.

A total of 16 species of Calanoida, 7 species of Cyclopoida, and 2 species of Harpacticoida were identified among the 24 samples (Supplementary Table 1). Most species were occasionally dominant, but six species, namely, Paracalanus parvus, Temora turbinata, Acrocalanus gibber, Temora stylifera, Euterpe acutifrons, and Acrocalanus gracilis, were dominant species with frequencies $\geq 4$ and dominance indices in the range of 0.02-0.21 (Table 3).

No obvious diel vertical migration was observed in copepods except for T. turbinata and P. parvus (Figures 5A-J), which apparently underwent diel vertical migration, especially on the first day (Figures 5K,L), but their mean depths, estimated following Frost and Bollens (1992), were not different between midnight and noon ( $p>0.05,2.9$ vs. $3.9 \mathrm{~m}$ and 4.1 vs. 4.6 $\mathrm{m}$, respectively) (Figures 5A,D). Day-to-day differences in the distribution pattern of copepods were apparent.

\section{Diel Variation in the Ingestion Rate}

The copepod gut $\mathrm{Chl} \alpha$ content showed diel variation patterns $(p<0.001)$; that is, the gut pigment content reached its highest values at dawn or noon and exhibited lower values at midnight and dusk (all $p<0.043$ between time), whereas there was no difference between layers ( $p=0.314$; two-way ANOVA, Figure 6). When the copepod gut $\mathrm{Chl} \alpha$ was integrated through layers, the trend appeared clear (Figure 6D).

The average contributions of phytoplankton groups to gut pigments were estimated by integrating all layers and time points, assuming that the instantaneous ingestion rate represented the average value during the 6-h period. Diatoms, accounting for an average of $32.9 \%$ of the total gut $\mathrm{Chl} \alpha$ content (1.8$72.6 \%$ ), were the most important group ( $p \leq 0.005)$, followed by prymnesiophytes and cyanobacteria, which accounted for $24.1 \%$ $(0-47.3 \%)$ and $19.4 \%(0-44.5)$, respectively $(p \leq 0.045$, two-way ANOVA; Figure 6).

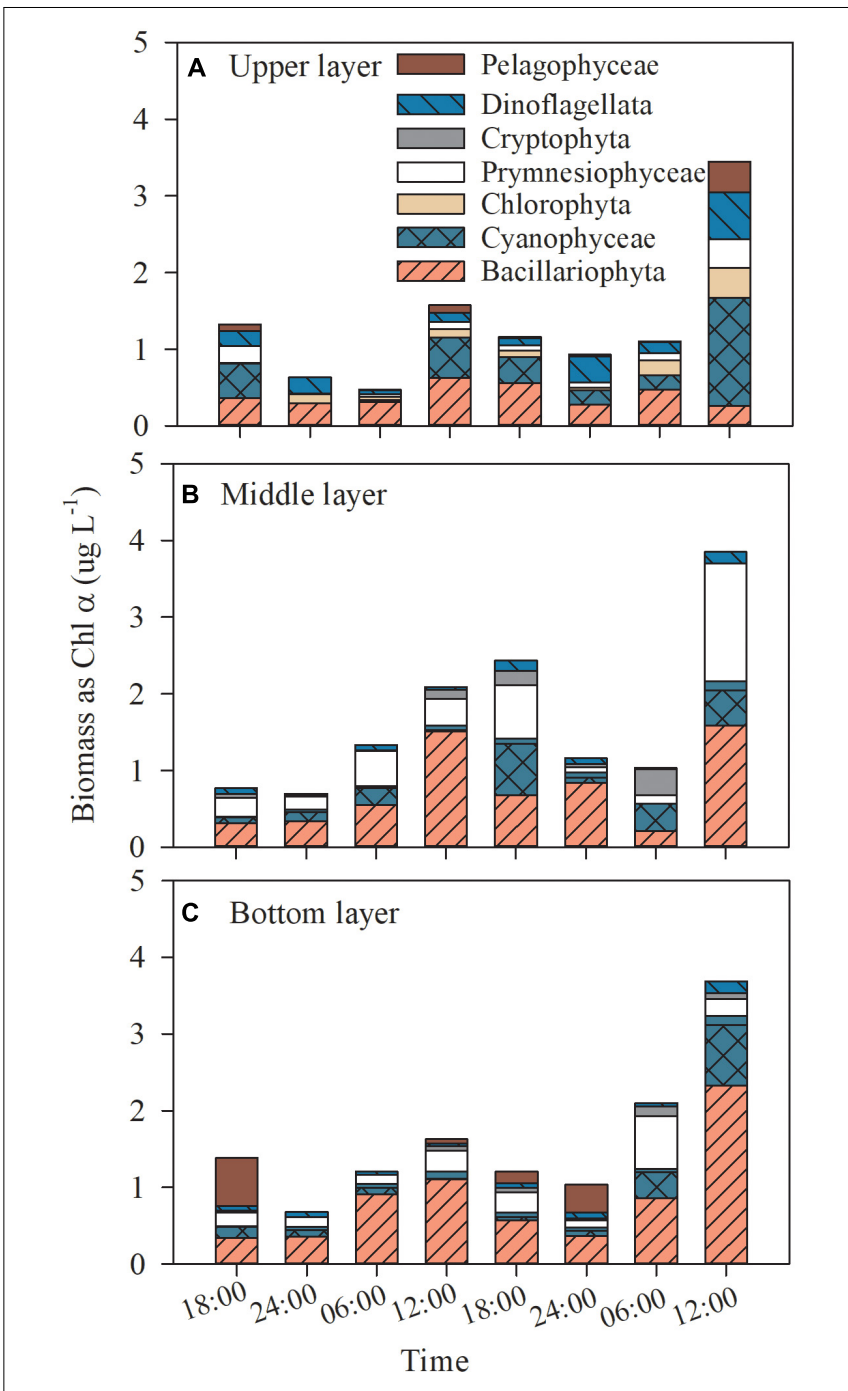

FIGURE $\mathbf{3}$ | Dial variation in the community composition of the phytoplankton assemblage in the upper layer (A), the middle layer (B), and the bottom layer (C) of Daya Bay during September 30 to October 2, 2014.

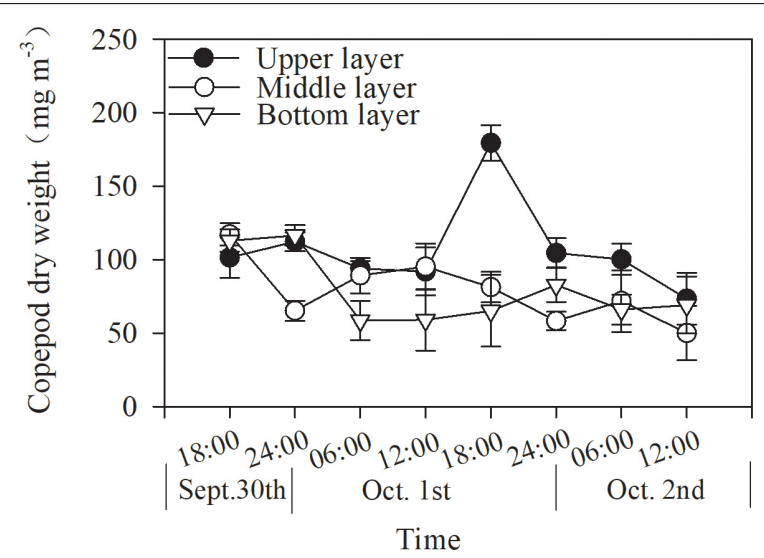

FIGURE 4 | Dial variation in copepod biomass in Daya Bay during September 30 to October 2, 2014. 
TABLE 3 | Predominant copepod species in the upper, middle, and bottom layers at the sampling station in Daya Bay during September 30 to October 2, 2014.

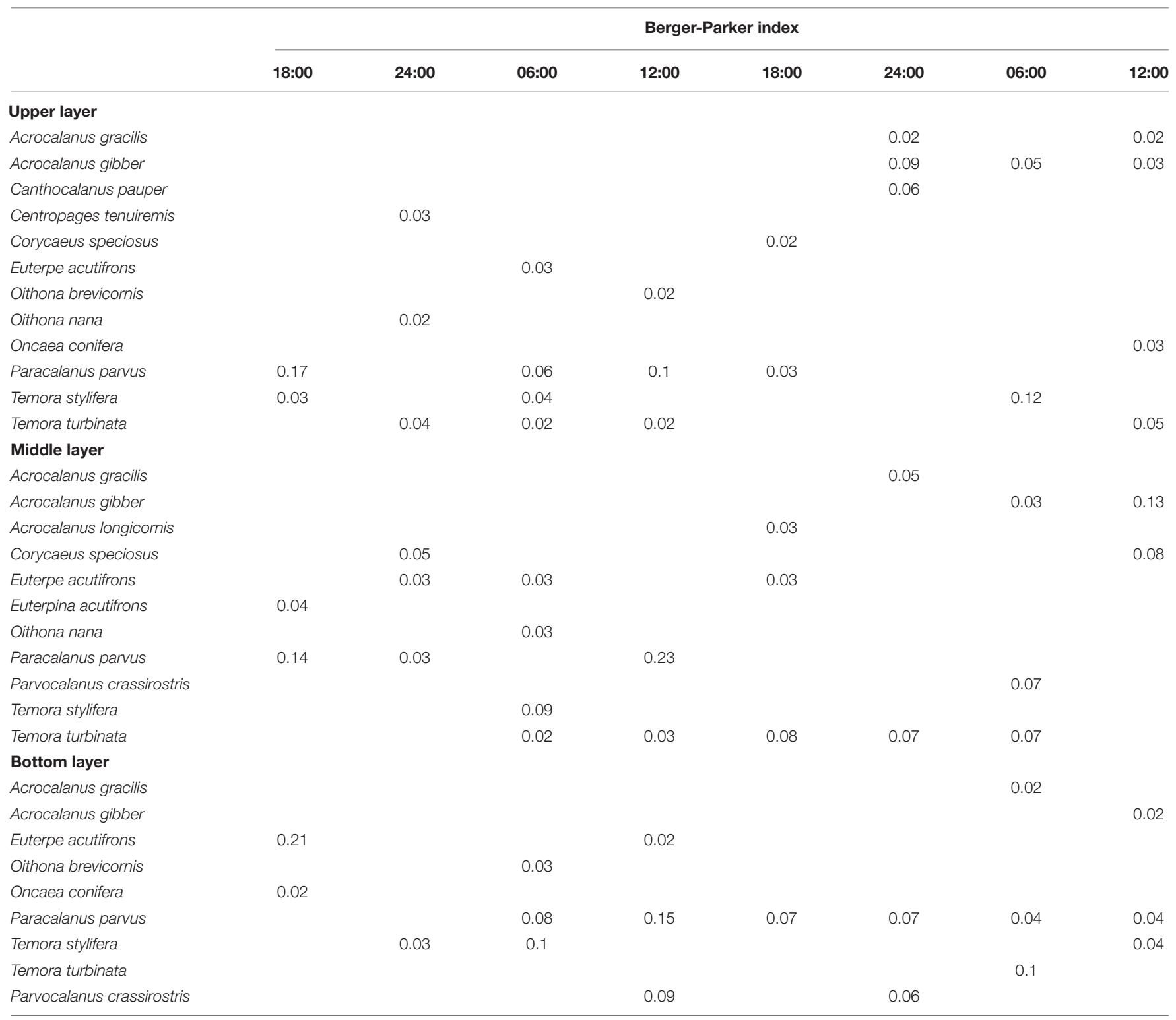

As there was no difference in gut $\mathrm{Chl} \alpha$ content between layers, ingestion rates of copepod were calculated for entire water column by integration through depth. The ingestion rate of the copepod assemblage ranged from $1.14 \pm 0.31$ to $6.91 \pm 2.85 \mathrm{ng}$ Chl $\alpha$ ind. ${ }^{-1} \mathrm{~h}^{-1}$ and showed significant diel variation. Ingestion rates were higher from dawn to noon than at other time points $(3.63 \pm 2.08-6.91 \pm 2.85$ vs. $1.14 \pm 0.31-3.48 \pm 2.17 \mathrm{ng} \mathrm{Chl} \alpha$ $\operatorname{cop}^{-1} \mathrm{~h}^{-1} ; p<0.001$, one-way ANOVA; Figure 7). The massspecific ingestion rate followed the same diel pattern as the individual ingestion rate ( $p=0.001$, Figure 7$)$.

Gut pigment content was closely linked to $\mathrm{Chl} \alpha$ concentration. Their relationship could be described with a linear function or the Michaelis-Menten equation $(p=0.015$ or 0.017 , respectively, Figure $\mathbf{8 A}$ ). The same correlation was observed for the ingestion rate and $\mathrm{Chl} \alpha$ concentration but with a closer relationship ( $p=0.005$ or 0.027 ; Figure $8 B$ ). The minimum saturation food concentrations for gut pigments and the ingestion rate were higher than the maximum ambient $\mathrm{Chl}$ $\alpha$ concentration $\left(3.85 \mu \mathrm{g} \mathrm{L}^{-1}\right)$ in this study. In particular, the ingestion rate of cyanobacteria and dinoflagellates by copepods varied significantly with the ambient $\mathrm{Chl} \alpha$ concentrations of these two groups in a positive, linear, and significant manner $(p<0.001$ and $=0.0334$, Pearson's correlation $)$.

\section{Grazing Selectivity}

Selectivity in each experiment was analyzed by comparing the frequency distributions of the all phytoplankton groups in the diet to those in the environment by means of a chi-square test. The difference was significant for all timepoints $(p \leq 0.004)$.

The selectivity indices for each of the main groups varied irregularly and greatly with time and layer (Figure 9), and based on the frequency of indices falling within the 


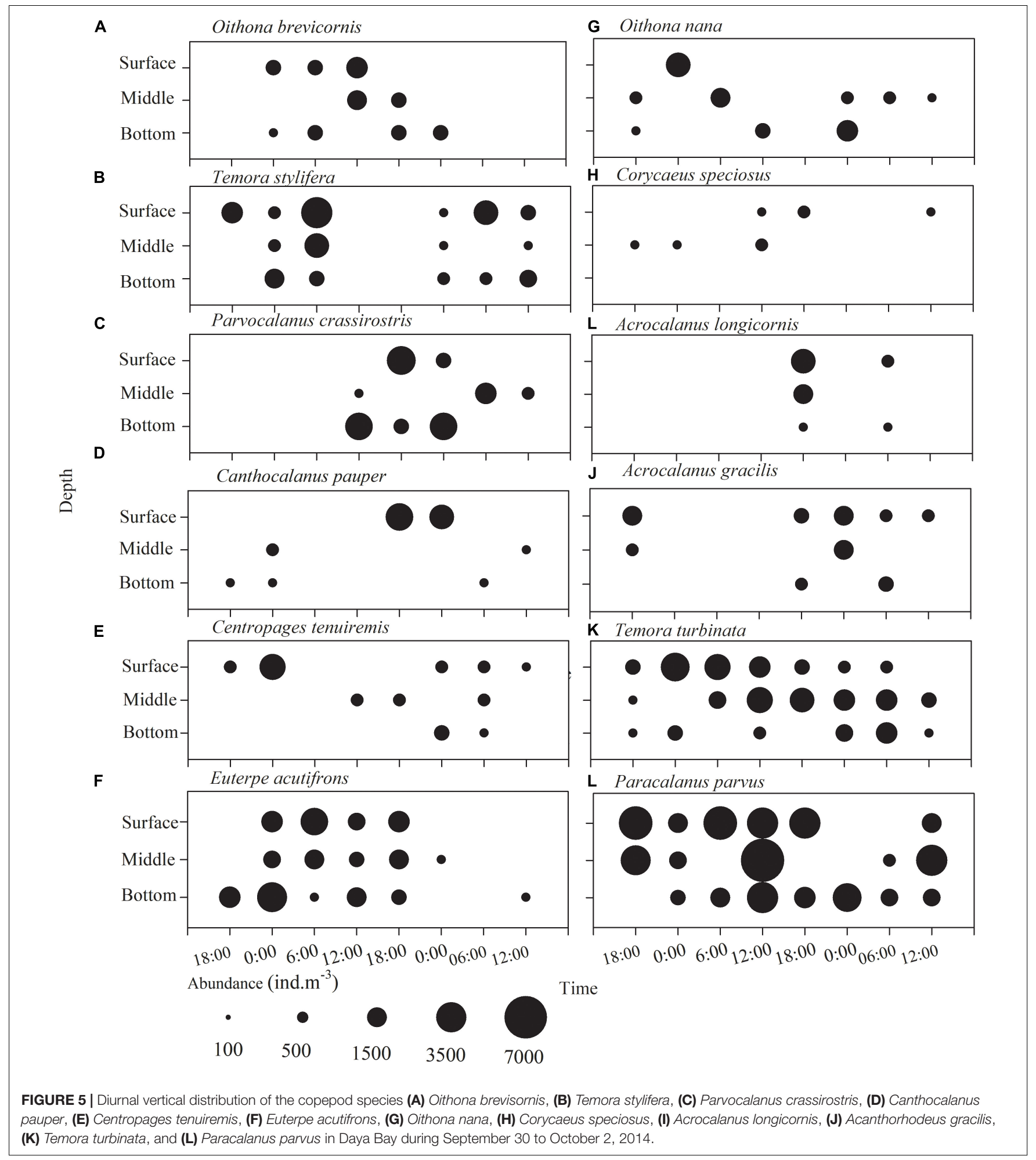

ranges of selectivity, the phytoplankton could be classified as showing a feeding preference, a weak preference, or avoidance. For prymnesiophytes, $63 \%$ of the selectivity values were $>+0.25$, indicating a strong feeding preference for the copepod assemblage. For diatoms, 25\% of the selectivity index values were in the range of $+0.25 \sim+1,12.5 \%$ in the range of $-1 \sim-0.25$, and $62.5 \%$ in the range of $-0.25 \sim+0.25$, suggesting a weak preference. For the other three classes, $63-75 \%$ of the selectivity index values fell within the range of $-1 \sim-0.25$, indicating feeding avoidance by copepods. 


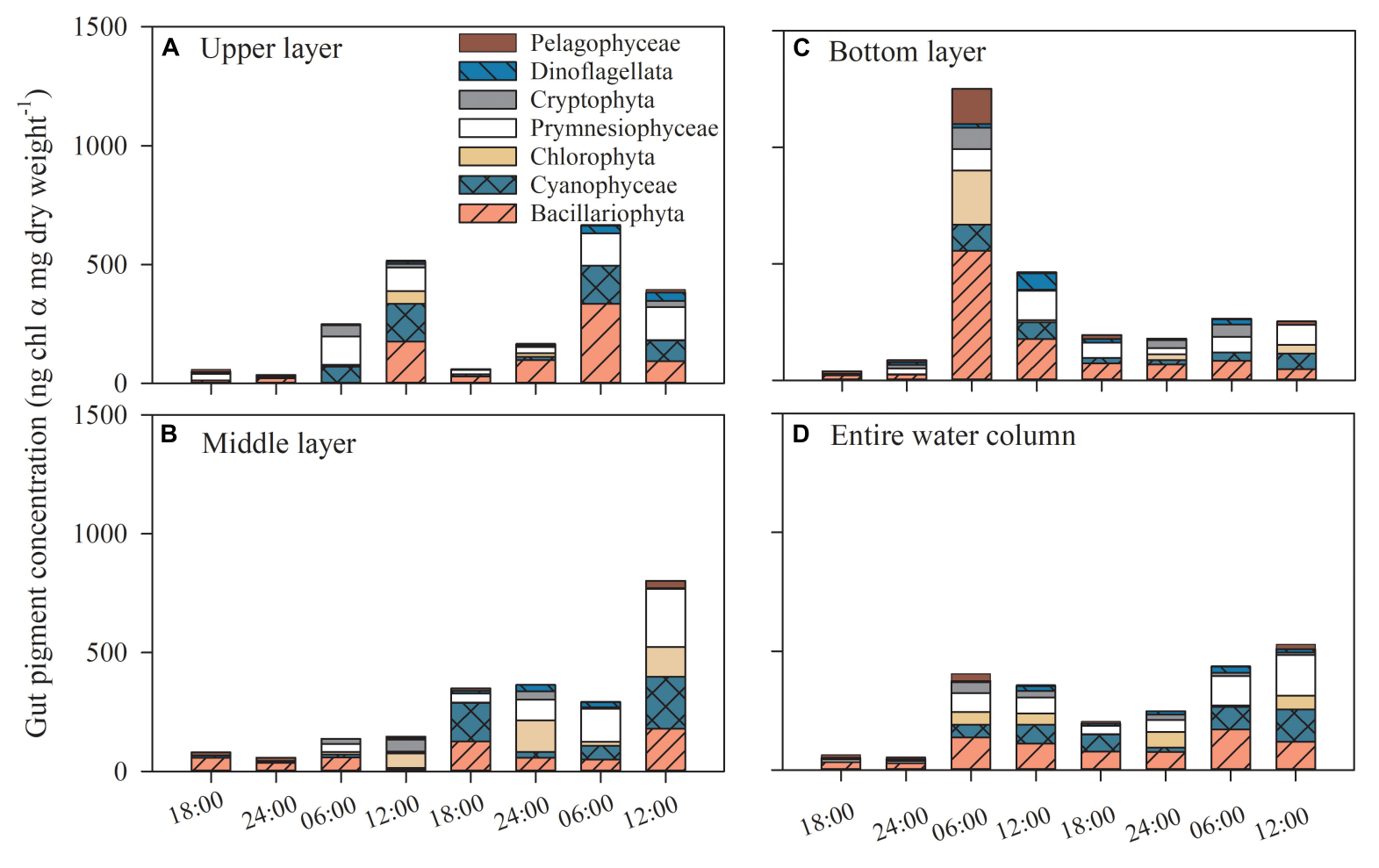

Time

FIGURE 6 | Dial variation in gut pigment contents and the contributions of phytoplankton groups to gut pigments in the (A) upper layer, (B) middle layer, (C) bottom layer, (D) entire water column of Daya Bay during September 30 to October 2, 2014.

Kolmogorov-Smirnov and Mann-Whitney tests showed the same grouping result except that feeding selection of copepod on diatoms was comparable to the cases of prymnesiophytes and chlorophytes ( $p=0.161$ and 0.083 , Table 4$)$.

\section{Grazing Pressure}

The total grazing pressure of the phytoplankton assemblage was $55 \%$ of the standing stock during the 48 -h study, representing the

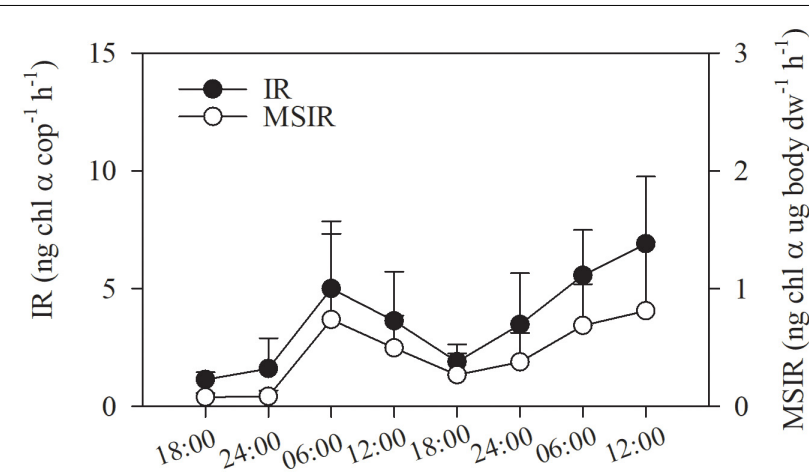

FIGURE 7 | Consumption of phytoplankton Chl $\alpha$ by the copepod assemblage in Daya Bay during September 30 to October 2, 2014: ingestion rate $(\mathrm{IR})$; mass-specific ingestion rate (MSIR). average of variable grazing pressures on specific phytoplankton groups. Grazing pressure on prymnesiophytes reached a very high value, $220 \%$, followed by that on diatoms, measuring $61 \%$. The other groups exhibited grazing pressures ranging from 16 to $47 \%$.

Grazing pressure fluctuated with phytoplankton group and time (Figure 10). While the higher values occurred at dawn in cyanobacteria and prymnesiophytes, but lack of statistical significance, no consistent trend was found in any of other groups (all $p>0.1$, one-way ANOVA; Figure 10).

\section{DISCUSSION}

The diel feeding rhythm of copepods was for the first time studied in Daya Bay during a period of $48 \mathrm{~h}$ in autumn. This study can be taken as a series of snapshots of the trophodynamics of copepods in this area as the marine system is very dynamic, so is the trophic interaction after all. The small copepods with body length $<1.5 \mathrm{~mm}$ were the dominant components of the copepod assemblage in the waters, following the findings for other marine systems (Williams et al., 1994; Hopcroft et al., 1998; Turner, 2004). The copepod assemblage exhibited higher feeding tendency at day time, which is seemly linked to variation pattern of their prey concentration, but not the diel vertical migration since copepods didn't show 

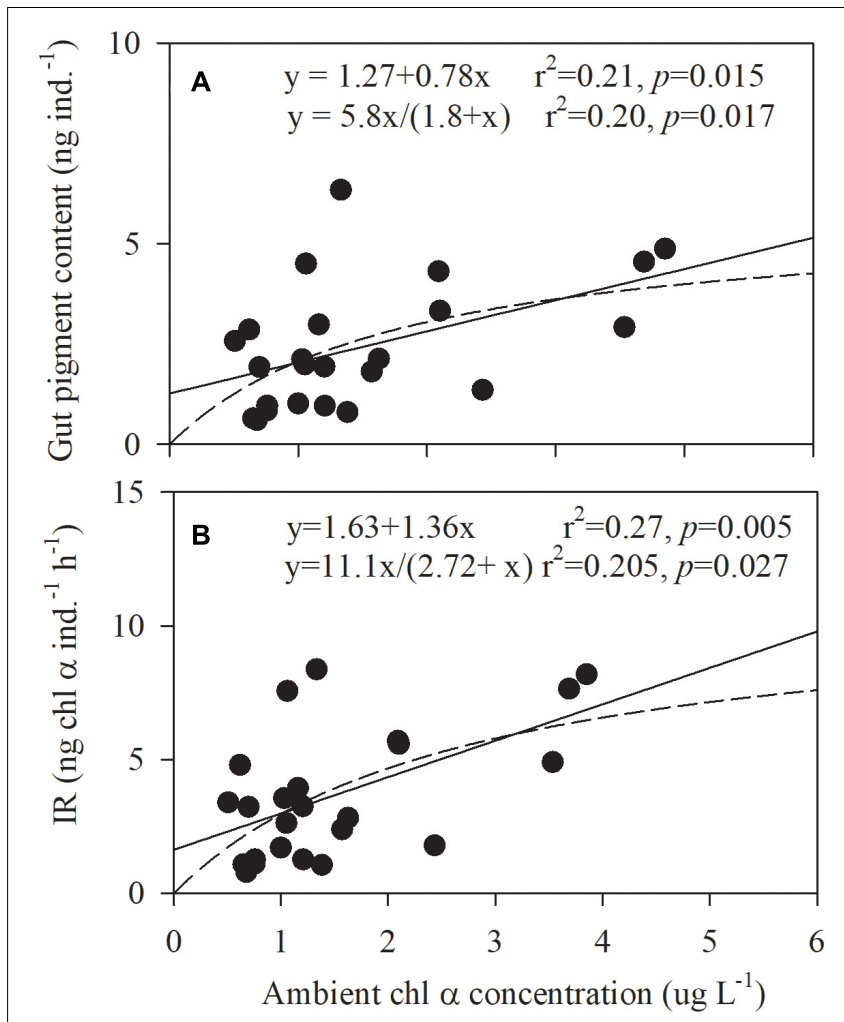

FIGURE 8 | Correlations between the (A) ingestion rate (IR) and ambient Chl $\alpha$ concentration and the (B) gut pigment contents and the ambient $\mathrm{Chl} \alpha$ concentration in Daya Bay during September 30 to October 2, 2014.

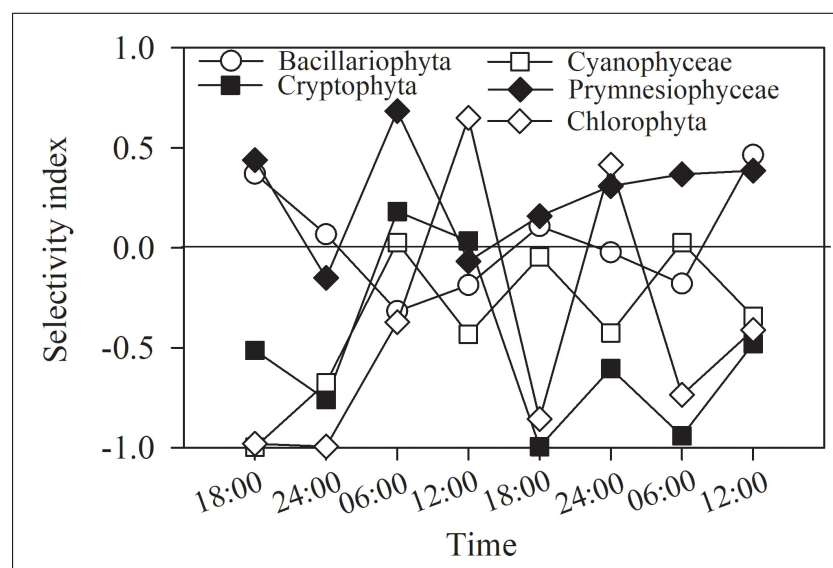

FIGURE 9 | Selectivity index of copepods for phytoplankton groups in entire water column of Daya Bay during September 30 to October 2, 2014.

distinct diel vertical distribution in this study. The copepod assemblage exerted strong grazing pressures on the main groups of phytoplankton and prymnesiophytes, but with different feeding tendencies toward them.

The coastal water column displayed a weak stratification during the study period as both of temperature and salinity varied significantly with depth. Water temperature difference between
TABLE 4 | $P$-values from Mann-Whitney tests for differences in selectivity index distributions between phytoplankton groups: diatoms (Dia.), cryptophytes (Cry.), cyanobacteria (Cya.), chlorophytes (Chl.), and prymnesiophytes (Pry.).

\begin{tabular}{lccccc}
\hline & Dia. & Cry. & Cya. & Chl. & Pry. \\
\hline Dia. & - & 0.021 & 0.028 & 0.083 & 0.161 \\
Cry. & - & - & 0.505 & 0.798 & 0.003 \\
Cya. & - & - & - & 0.721 & 0.005 \\
Chl. & - & - & - & - & 0.046
\end{tabular}

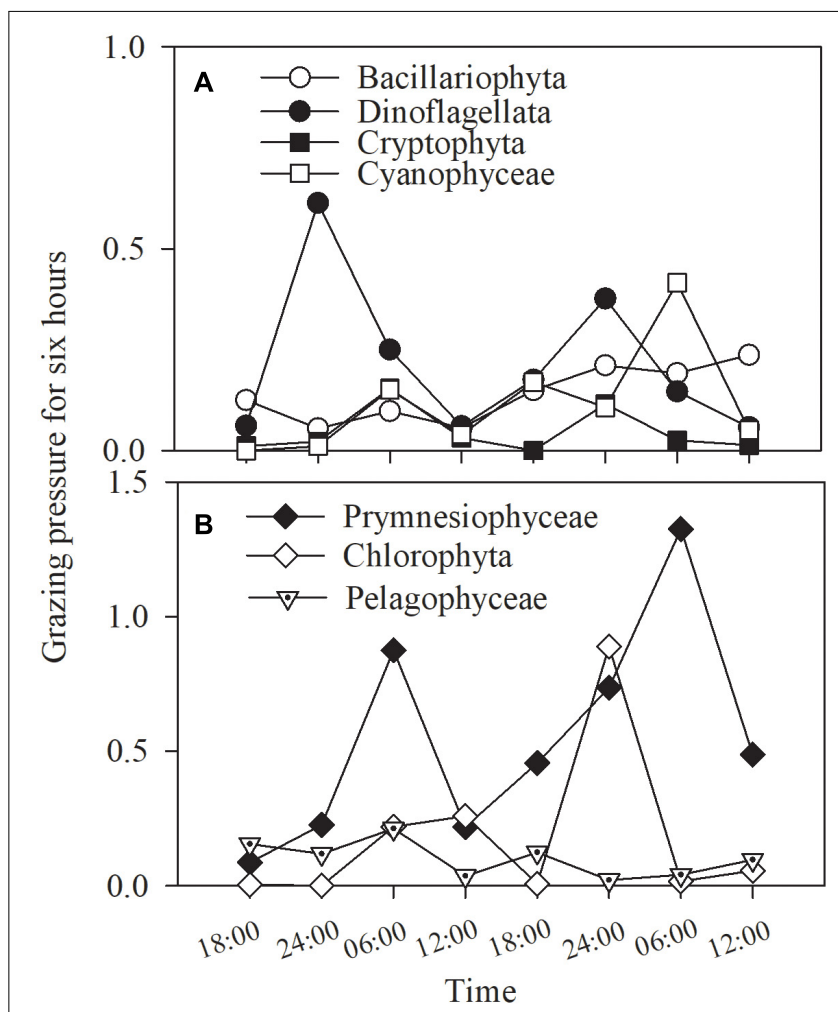

FIGURE 10 | Grazing pressure of the copepod assemblage on (A) Bacillariophyta, Dinoflagellata, Cryptophyta, Cyanophyceae and (B) Prymnesiophyceae, Chlorophyta, Pelagophyceae for $6 \mathrm{~h}$ in Daya Bay during September 30 to October 2, 2014.

the upper and bottom layer reached 1.2 and $0.9^{\circ} \mathrm{C}$ at daytime and night time, respectively, which is comparable to the findings at the adjacent area by Sun et al. (2011). The difference in salinity between the upper and bottom layers was close to reported value in the literatures $(0.2-0.5$ vs. $0.2-0.3)$ at the sampling site (Li, 2009). In Daya Bay, the annual maximum surface sea water temperature $\left(\sim 30^{\circ} \mathrm{C}\right)$ generally occurs in summer and early autumn after Daya Bay Nuclear Power Plant (DNPP) and Lingao Nuclear Power Plant (LNPP) have been operated since 1993 and 2003, respectively (Figure 1). Besides the sunlight, discharge of the waste warm waters from these two nuclear power plants contributes to formation and maintenance of the stratification of water column in the adjacent coastal waters during summer and autumn by increasing water temperature at the depth of $0 \sim 4 \mathrm{~m}$. 
Small copepods with body lengths $<1.5 \mathrm{~mm}$, including small calanoid genus Paracalanus, Temora, Acrocalanus and the harpacticoid species Euterpe acutifrons, accounted for 73.9-100\% of the total community biomass in the shallow south western coastal waters of Daya Bay, which is consistent with findings for the same system or in other pelagic systems in previous studies (Hopcroft et al., 1998; Turner, 2004; Liu et al., 2013; Han, 2015; Cheng, 2019). In the early study by Liu et al. (2013), the dominance of other two small copepod species Paracalanus crassirostris and Oithona tenuis were highlighted with contribution of nearly $80 \%$ to the zooplankton biomass in the adjacent area. The stratification of water column and the high water temperature during the early autumn is proposed to promote the proliferation of small copepods and led to their dominance in the copepod community in this area, just as was reported in other systems (Sullivan, 1993; Drira et al., 2014). However, the abundance of small copepods had been underestimated greatly in most early studies in this area by using coarse mesh nets. Wu et al. (2011) found that when using 330and $100-\mu \mathrm{m}$-mesh plankton nets, copepod abundance differed by two orders of magnitude. More specifically, Li et al. (2018) demonstrated that when using $500-\mu \mathrm{m}$-mesh plankton nets, the densities of $P$. parvus, $P$. crassirostris, and T. turbinate in this area in fall were only $0.5-0.7 \%$ of the abundances measured in our study. Underestimation of the abundance of small copepods will inevitably lead to underappreciation of their functional importance in this ecosystem.

Diel feeding rhythm of copepods was tested for the first time in this area in this present study. The copepod assemblage had the average gut pigment content of a 10 -fold variation (0.6-6.3 ng Chl $\alpha$ ind. $\left.^{-1}\right)$, comparable to the range $\left(0.30-4.81 \mathrm{ng} \mathrm{Chl} \alpha\right.$ ind. $\left.{ }^{-1}\right)$ reported for small copepod species in other marine systems (Dam and Peterson, 1988; Tang et al., 1994; Tan et al., 2004) but slightly higher than that (1.79-2.99 $\mathrm{ng}$ Chl $\alpha \mathrm{mg}$ wet weight ${ }^{-1}$ ) in the study by Champalbert et al. (2003) in a low-chlorophyll zone of the equatorial Pacific Ocean when converted into wet weight specific gut pigment concentration. Correspondingly, the ingestion rate varied in the range of $0.79-8.4 \mathrm{ng} \mathrm{Chl} \alpha$ ind. ${ }^{-1} \mathrm{~h}^{-1}$, which falls into the broad range of $0.058-41.6 \mathrm{ng}$ Chl $\alpha$ ind. $^{-1} \mathrm{~h}^{-1}$ in the literature for specific copepod species (Kiørboe et al., 1985; Arinardi et al., 1990; Durbin et al., 1990; Lee et al., 2012). Generally, the gut pigment content of copepods was higher at dawn or at noon than at dusk or at midnight, with 10- and 21-fold differences between the maximum and minimum values. This diurnal feeding pattern is similar to those reported in the studies by Kiørboe et al. (1985) and Champalbert et al. (2003) on copepod assemblages or individual species but in contrast to the nocturnal feeding pattern commonly reported in most previous studies. In this study, the diurnal feeding pattern was consistent with the variation in ambient $\mathrm{Chl} \alpha$ concentration, and furthermore, a close correlation was observed between the gut pigment content and $\mathrm{Chl} \alpha$ concentration, both supporting the diel feeding rhythm being dependent on food availability. The diurnal feeding rhythms of the copepod assemblage in early autumn, nevertheless may not be extrapolated to other seasons, as even the same species alters dial gut pigment rhythms with the season (Tang et al., 1994).
Diel feeding rhythms are usually shaped by food environments, the risk of predation, and endogenic factors, and the interactive effects of these external and endogenic factors lead to apparent feeding rhythms. While Acartia tonsa maintained its diel feeding rhythm independently of food level (Durbin et al., 1990), other species changed their diel feeding rhythms at different developmental stages and food concentrations (Daro, 1988; Tiselius, 1988). Furthermore, different copepod species commonly exhibit diverse diel feeding patterns in the same food environment, emphasizing the determinant roles of specific feeding habits or other endogenic factors (Tiselius, 1988; Kouassi et al., 2001; Lee et al., 2012). The predation pressure was not evaluated in Daya Bay in this study, but both the lack of inter-layer difference in copepod biomass and the insignificant nocturnal up-moving of copepod suggest that copepod assemblage may not face strong predation pressure. In the past twenty years, the number of fish species and abundance of fish stocks have been declining (Zhang et al., 2020). Alternatively, fishes usually migrate out of the bay in autumn and winter (Wang et al., 2010).

Generally, copepod species hardly vary in their vertical distributions, although tendencies for increasing abundance were observed during nighttime in the upper layers for T. turbinata and $P$. parvus. This finding is in agreement with that from the earlier study by Huang et al. (2010) for this area in the same season. P. parvus also showed no significant diel vertical migration in an early study in Tolo Harbor (Tang et al., 1994). As for the copepod assemblage, it is noticeable that there was a biomass peak at 18:00 on the second day. This peak corresponds to high abundances of the dominant genus Paracalanus, E. acutifrons, A. longicornis, A. gracilis, and C. pauper, and the last three species occurred sporadically at the site, suggesting that patchy distribution and advection of copepods in this area. Because of labor limitation, no more time points than four each day were set, which may compromise conclusive inferences of the vertical distribution of copepods in this study.

The copepod assemblage exerted moderate integrated grazing pressure in this study, consuming 55\% of the phytoplankton standing stock. Applying the productivity (199.2 $\mathrm{mg} \mathrm{C} \mathrm{m}^{2} \mathrm{~d}^{-1}$ ) from the study by Liu et al. (2012) for the same area and assuming a $\mathrm{C} / \mathrm{Chl} \alpha$ ratio of 50 , the grazing pressure is equal to $25.3 \%$ of the primary productivity. Tan et al. (2004) reported an average grazing pressure of $26 \pm 30 \%$ as phytoplankton standing stock in an adjacent area.

The phylum-specific grazing pressure of copepods, which was previously only minimally addressed, was further evaluate applying the diagnostic pigment analysis in this study. The copepod assemblage exerted grazing pressure of $16-220 \%$ on different phytoplankton groups. Diatoms ranked the most important prey, followed by prymnesiophytes and cyanobacteria, different from the phytoplankton community composition, indicating grazing selection in copepods. Prymnesiophytes is just a minor group with contribution of $5.5 \%$ of total $\mathrm{Chl}$ $\alpha$, but accounted for $24 \%$ of the gut Chl $\alpha$. This phylum of algae is commonly thought to be unpalatable to copepods due 
to its small size or toxic metabolites (Weisse et al., 1994), but the Phaeocystis genus was found to be ingested by some copepod species as colonies and solitary cells and even as preferential food items in a few studies (Weisse et al., 1994; Nejstgaard et al., 1994; Cotonnec et al., 2001). Although the species composition of Prymnesiophyceae was not determined in this study, Phaeocystis globosa and Prymnesiophycea parvum are known to often form harmful blooms in adjacent areas (Chen et al., 1999; Guo et al., 1996). Controversies exist regarding the availability of these two Prymnesiophyceae species to copepods. It seems that the consumptive interaction between prymnesiophytes and copepods greatly depends on the size and physiological state of both participants. P. parvum impedes grazing in Acartia species and Eurytemora affinis, according to Nejstgaard and Solberg (1996) and Sopanen et al. (2006), but it can be consumed by E. affinis as a unialgal diet or algal mixture, as reported by Koski et al. (1999). During blooms, copepods show significant ingestion of single cells but low ingestion of colonies (Hansen and van Boekel, 1991; Gasparini et al., 2000; Cotonnec et al., 2001). The high degree of grazing on prymnesiophytes (220\% of the standing stock) in this study may be linked to the high consumption of copepods on the cells in solitary form.

Cyanobacteria were avoided by the copepod assemblage in this study despite its importance in the gut content of copepod. In recent years, the contribution of cyanobacteria to phytoplankton assemblages has been increasingly reported in the waters of Daya Bay, and blooms of Trichodesmium, Synechococcus, Microcystis, and Nostoc have caused great concern (Song et al., 2009; Wang et al., 2018). Copepods show different feeding tendencies for different cyanobacterial species. Trichodesmium was reported as the dominant genus in autumn in Daya Bay in previous studies (Wang et al., 2018; Wu et al., 2020), but it is speculated that copepods may avoid these filamentous cyanobacteria when alternative algae are available since consuming Trichodesmium has sublethal effects on A. tonsa (Guo and Tester, 1994). Pico-sized Synechococcus and non-toxic Microcystis are usually grazed preferentially in mixtures of other species (DeMott and Moxter, 1991; Motwani and Gorokhova, 2013; Shoemaker and Moisander, 2017), while toxic Microcystis is discriminated against by copepods (DeMott and Moxter, 1991). It is speculated that unpalatable species constituted the majority of the cyanobacteria during the study period.

Cryptophytes and chlorophytes, the two main groups of phytoplankton in the community, were avoided by copepods in this study. McLeroy-Etheridge and McManus (1999) argued that the potential destruction of the diagnostic carotenoid of cryptophytes, alloxanthin, reaches $37-65 \%$ during copepod feeding, which may lead to underestimation of the contribution of algae to the copepod diet. Alternatively, even though cells of cryptophytes and chlorophytes are nutritious, copepods may exhibit a species-specific grazing response to these small cells (Cotonnec et al., 2001). In a study by Holmes (2018) using high-throughput genetic sequencing, cryptophytes were absent in the gut contents of Pseudodiaptomus forbesi. Additionally, as the feeding selectivity of the copepod assemblage reflects its integrated feeding tendency, variation in copepod community structure obscures feeding selectivity of a specific species on phytoplankton groups.

\section{CONCLUSION}

The diel feeding rhythm and grazing selectivity of the planktonic copepod assemblage of Daya Bay were examined during a 48$\mathrm{h}$ study in early autumn. The importance of small $(<1.5 \mathrm{~mm})$ planktonic copepods was evident from their proportion (73.9$100 \%)$ of the total mesozooplankton abundance. The copepod assemblage generally exhibited a diurnal feeding pattern, characterized by a higher gut pigment content and ingestion rate during the daytime, consistent with variation in the ambient Chl $\alpha$ concentration, indicating that food level controlled the diel feeding rhythm of copepods. Grazing loss by the copepod assemblage accounted for $55 \%$ of the phytoplankton standing stock, and diatoms, prymnesiophytes and cyanobacteria were the main prey. The copepod assemblage showed a strong grazing preference for prymnesiophytes but avoidance of cryptophytes and cyanobacteria. The grazing tendency of dominant small copepods on small phytoplankton and the high grazing effect on the phytoplankton community imply that copepods control the succession of the phytoplankton community and can efficiently transfer carbon and nutrients from these primary producers in the Daya Bay ecosystem.

\section{DATA AVAILABILITY STATEMENT}

The raw data supporting the conclusions of this article will be made available by the authors, without undue reservation.

\section{AUTHOR CONTRIBUTIONS}

$\mathrm{XH}$ and $\mathrm{MC}$ conceived, designed the analysis, and wrote the manuscript. ZW, ZB, and $\mathrm{LH}$ attended field works and data analysis. All authors contributed to the article and approved the submitted version.

\section{FUNDING}

This research was supported by a grant from the Natural Science Foundation of Guangdong (No. 2021A1515011384) to XH.

\section{ACKNOWLEDGMENTS}

We thank the three reviewers for their very constructive comments.

\section{SUPPLEMENTARY MATERIAL}

The Supplementary Material for this article can be found online at: https://www.frontiersin.org/articles/10.3389/fmars.2021. 658664/full\#supplementary-material 


\section{REFERENCES}

Arinardi, O. H., Baars, M. A., and Oosterhuis, S. S. (1990). Grazing in tropical copepods measured by gut fluorescence, in relation to seasonal upwelling in the Banda Sea (Indonesia). Neth. J. Sea. Res. 25, 545-560. doi: 10.1016/00777579(90)90077-t

Brotas, V., and Plante-Cuny, M. R. (1998). Spatial and temporal patterns of microphytobenthic taxa of estuarine tidal flats in the Tagus Estuary (Portugal) using pigment analysis by HPLC. Mar. Ecol. Prog. Ser. 171, 43-57. doi: 10.3354/ meps 171043

Castonguay, M., Plourde, S., Robert, D., Runge, J. A., and Fortier, L. (2008). Copepod production drives recruitment in a marine fish. Can. J. Fish. Aquat. Sci. 65, 1528-1531. doi: 10.1139/F08-126

Champalbert, G., Neveux, J., Gaudy, R., and LeBorgne, R. (2003). Diel variations of copepod feeding and grazing impact in the high-nutrient, low-chlorophyll zone of the equatorial Pacific Ocean $\left(0^{\circ} ; 3^{\circ} \mathrm{S}, 180^{\circ}\right)$. J. Geophy. Res. 108:8145.

Chen, B. H., Xu, Z. H., Zhou, Q. L., Zhou, Q. L., Chen, C. P., Gao, Y. H., et al. (2010). Long-term changes of phytoplankton community in Xiagu waters of Xiamen, China. Acta Oceanol. Sin. 29, 104-114. doi: 10.1007/s13131-010-0081-4

Chen, J., Huang, B., Liu, Y., Cao, Z., and Hong, H. (2006). Phytoplankton community structure in the transects across east China Sea and northern South China Sea determined by analysis of HPLC photosynthetic pigment signatures. Adv. Earth. Sci. 21, 738-746.

Chen, J. F., Xu, N., Jiang, T., Wang, Y., Wang, Z., and Qi, Y. (1999). A report of Phaeocystis globose bloom in coastal water of Southeast China. J. Jinan Univ. 20, 124-129.

Cheng, F. (2019). Can Ecological Stoichiometric Niche and Feeding Habit Explain Predominance of Marine Cladocerans in Zooplankton Community of the Daya Bay. Master's thesis. Guangzhou: Jinan University.

Chiba, S. (2019). Relation between miniaturization of phytoplankton and longterm variation of water quality in ise bay. J. Yokkaichi U. 32, 139-155. doi: 10.24584/jyu.32.1_139

Costalago, D., Navarro, J., Álvarez-Calleja, I., and Palomera, I. (2012). Ontogenetic and seasonal changes in the feeding habits and trophic levels of two small pelagic fish species. Mar. Ecol. Prog. Ser. 460, 169-181. doi: 10.3354/meps09751

Cotonnec, G., Brunet, C., Sautour, B., and Thoumelin, G. (2001). Nutritive value and selection of food particles by copepods during a spring bloom of Phaeocystis sp. in the English Channel, as determined by pigment and fatty acid analyses. J. Plank. Res. 23, 693-703. doi: 10.1093/plankt/23.7.693

Cowles, T. J. (1979). The feeding response of copepods from the Peru upwelling system: food size selection. J. Mar. Res. 37, 601-622.

Dagg, M. J., and Wyman, K. D. (1983). Natural ingestion rates of the copepods Neocalanus plumchrus and N. cristatus calculate d from gut contents. Mar. Ecol. Prog. Ser. 13, 37-46. doi: 10.3354/meps013037

Dam, H. G., and Peterson, W. T. (1988). The effect of temperature on the gut clearance rate constant of planktonic copepods. J. Exp. Mar. Biol. Ecol. 123, 1-14. doi: 10.1016/0022-0981(88)90105-0

Daro, M. H. (1988). Migratory and grazing behavior of copepods and vertical distribution of phytoplankton. Bull. Mar. Sci. 43, 710-729.

DeMott, W. R., and Moxter, F. (1991). Foraging cyanobacteria by copepods: responses to chemical defense and resource abundance. Ecology 72, 1820-1834. doi: $10.2307 / 1940981$

Drira, Z., Hassen, M. B., Ayadi, H., and Aleya, L. (2014). What factors drive copepod community distribution in the Gulf of Gabes, Eastern Mediterranean Sea? Environ. Sci. Pollut. Res. 21, 2918-2934. doi: 10.1007/s11356-0132250-4

Durbin, A. G., Durbin, E. G., and Wlodarczyk, E. (1990). Diel feeding behavior in the marine copepod Acartia tonsa in relation to food availability. Mar. Ecol. Prog. Ser. 68, 23-45. doi: 10.3354/meps068023

Frost, B. W, and Bollens, S. M. (1992). Variability of diel vertical migration in the marine planktonic copepod Pseudocalanus newmani in relation to its predators. Can. J. Fish. Aquat. Sci. 49, 1137-1141. doi: 10.1139/f92-126

Fuller, J. L. (1937). The feeding rate of Calanus finmarchicus in relation to environmental conditions. Biol. Bull. Mar. Biol. Lab Woods Hole 72, 233-246. doi: $10.2307 / 1537257$

Gasparini, S., Daro, M. H., Antajan, E., Tackx, M., Rousseau, V., Parent, J.-Y., et al. (2000). Mesozooplankton grazing during the Phaeocystis globosa bloom in the southern bight of the North Sea. J. Sea. Res. 43, 345-356. doi: 10.1016/s13851101(00)00016-2

Guo, C., and Tester, P. A. (1994). Toxic effect of the bloom-forming Trichodesmium sp. (Cyanophyta) to the copepod Acartia tonsa. Nat. Toxins 2, 222-227. doi: 10.1002/nt.2620020411

Guo, M., Harrison, P. J., and Taylor, F. J. R. (1996). Fish kills related to Prymnesium parvum N. Carter (Haptophyta) in the People's Republic of China. J. Appl. Phycol. 8, 111-117. doi: 10.1007/bf02186313

Han, L. (2015). The Distribution and Grazing Pattern of Crustacean Mesozooplankton in Daya Bay. Master's thesis. Guangzhou: Jinan University.

Hansen, F. C., and van Boekel, W. H. M. (1991). Grazing pressure of the calanoid copepod Temora longicornis on a Phaeocystis-dominated spring bloom in a Dutch tidal inlet. Mar. Ecol. Prog. Ser. 78, 123-129. doi: 10.3354/meps078123

Harding, G. C., Vass, W. P., and Hargrave, B. T. (1986). Diel vertical movements and feeding activity of zooplankton in St. Georges Bay, N.S., using net tows and a newly developed passive trap. Can. J. Fish. Aquat. Sci. 43, 952-967. doi: 10.1139/f86-118

Hayward, T. L. (1980). Spatial and temporal feeding patterns of copepods from the North Pacific Central Gyre. Mar. Biol. 58, 295-309. doi: 10.1007/bf00390778

He, X., and Peng, X. (2012). Spatial variability of summer and autumn phytoplankton community structure in Xiamen Western Bay based on pigment analysis. Acta. Oceanol. Sin. 31, 1-11. doi: 10.1016/s0278-4343(02)00173-5

Holmes, A. E. (2018). High-Throughput Sequencing Reveals Unexpected Phytoplankton Prey of an Estuarine Copepod. M.Sc. thesis, Department of Biology. San Francisco, CA: San Francisco State University.

Hopcroft, R. R., Roff, J. C., and Lombard, D. (1998). Production of tropical copepods in Kingston Harbour, Jamaica: the importance of small species. Mar. Biol. 130, 593-604. doi: 10.1007/s002270050281

Huang, D., Guo, Z., Chen, J., Yu, X., Qi, Y., Qi, S., et al. (2010). Vertical distribution and seasonal variations of biomass of zooplankton in Daya Bay water. Mar. Environ. Sci. 29, 825-828.

Isari, S., and Saiz, E. (2011). Feeding performance of the copepod Clausocalanus lividus. J. Plankton Res. 33, 715-728. doi: 10.1093/plankt/fbq149

Ivlev, V. S. (1961). Experimental Ecology of the Feeding of Fishes. New Haven: Yale University Press.

Kibirige, I., and Perisinotto, R. (2003). In situ feeding rates and grazing impact of zooplankton in a South African temporarily open estuary. Mar. Biol. 142, 357-367. doi: 10.1007/s00227-002-0963-x

Kiørboe, T., Møhlenberg, F., and Riisgård, H. U. (1985). In situ feeding rates of planktonic copepods: a comparison of four methods. J. Exp. Mar. Biol. Ecol. 88, 67-81. doi: 10.1016/0022-0981(85)90202-3

Kleppel, G. S., Burkart, C. A., Carter, K., and Thomas, C. (1996). Diets of calanoid copepods on the West Florida continental shelf: relationships between food concentration, food composition and feeding activity. Mar. Biol. 127, 209-217. doi: 10.1007/bf00942105

Koski, M., Rosenberg, M., Viitasalo, M., Tanskanen, S., and Sjölund, U. (1999). Is Prymnesium patelliferum toxic for copepods?-Grazing, egg production and egestion of the calanoid copepod Eurytemora affinis in mixtures of 'good' and 'bad' food. ICES J. Mar. Sci. 56(Suppl.), 131-139. doi: 10.1006/jmsc.1999. 0621

Kouassi, E., Pagano, M., Saint Jean, L., Arfi, R., and Bouvy, M. (2001). Vertical migrations and feeding rhythms of Acartia clausi and Pseudodiaptomus hessei (Copepoda: Calanoida) in a tropical lagoon (Ebrie', Cote d'Ivoire). Estuar. Coast. Mar. Sci. 52, 715-728.

Lee, D. B., Song, H. Y., Park, C., and Choi, K. H. (2012). Copepod feeding in a coastal area of active tidal mixing: diel and monthly variations of grazing impacts on phytoplankton biomass. Mar. Ecol. 33, 88-105. doi: 10.1111/j.14390485.2011.00453.x

Li, L. (2009). Ecological Studies on Daya Bay and Pearl River Estuary, the Most Frequent Harmful Algal Bloom Occurrence Areas in the Coasts. MSc thesis. Guangzhou: Jinan University.

Li, Y., Han, L., Chen, M., and Tong, M. -M. (2018). The mesozooplankton commnutiy structure and their herbivory in Daya Bay. Oceanol. Limnol. Sin. 49, 839-850.

Liu, H., Li, K., Huang, H., Song, X., Yin, J., and Huang, L. (2013). Seasonal community structure of mesozooplankton in the Daya Bay, South China Sea. J. Ocean Univ. China 12, 452-458. doi: 10.1007/s11802-013-1991-5 
Liu, H. X., Song, X. Y., Huang, L. M., and Zhong, Y. (2012). Using primary productivity as an index of coastal eutrophication: a case study in Daya Bay. Water Environ. J. 26, 235-240. doi: 10.1111/j.1747-6593.2011.00281.x

Longhurst, A. R. (1985). The structure and evolution of plankton communities. Prog. Oceanogr. 15, 1-35. doi: 10.1016/0079-6611(85)90036-9

Mackey, M. D., Higgins, H. W., Mackey, D. J., and Wright, S. W. (1997). "CHEMTAX user's manual: a program for estimating class abundances from chemical markers-application to HPLC measurements of phytoplankton pigments," in CSIRO Marine Laboratories Report 229, Hobart.

Magurran, A. E. (1988). Ecological Diversity and its Measurement. Princeton, NJ: Princeton University Press.

McLeroy-Etheridge, S. L., and McManus, G. B. (1999). Food type and concentration affect chlorophyll and carotenoid destruction during copepod feeding. Limnol. Oceanogr. 44, 2005-2011. doi: 10.4319/lo.1999.44.8.2005

Motwani, N. H., and Gorokhova, E. (2013). Mesozooplankton Grazing on Picocyanobacteria in the Baltic Sea as inferred from molecular diet analysis. PLoS One 8:e79230. doi: 10.1371/journal.pone.0079230

Nejstgaard, J. C., and Solberg, P. T. (1996). Repression of copepod feeding and fecundity by the toxic haptophyte Prymnesium patelliferum. Sarsia 81, 339-344. doi: 10.1080/00364827.1996.10413631

Nejstgaard, J. C., Witte, H. J., van der Wal, P., and Jacobsen, A. (1994). Copepod grazing during a mesocosm study of an Emiliania huxleyi (Prymnesiophyceae) bloom. Sarsia 79, 369-377. doi: 10.1080/00364827.1994.10413568

Olivares, M., Tiselius, P., Calbet, A., and Saiz, E. (2020). Non-lethal effects of the predator Meganyctiphanes norvegica and influence of seasonal photoperiod and food availability on the diel feeding behaviour of the copepod Centropages typicus. J. Plankton Res. 42, 1-10. doi: 10.1093/plankt/fbaa051

Pagano, M., Champalbert, G., Aka, M., Kouassi, E., Arfi, R., Got, P., et al. (2006). Herbivorous and microbial grazing pathways of metazooplankton in the Senegal River Estuary (West Africa). Estuar. Coast. Shelf Sci. 67, 369-381. doi: 10.1016/j.ecss.2005.10.018

Peterson, W. T., Painting, S. J., and Hutchings, L. (1990). Diel variations in gut pigment content, diel vertical migration and estimates of grazing impact for copepods in the southern Benguela upwelling region in October 1987. J. Plankton Res. 12, 259-281. doi: 10.1093/plankt/12.2.259

Plante-Cuny, M. R., Barranguet, C., Bonin, D., and Grenz, C. (1993). Does chlorophyllide a reduce reliability of chlorophyll a measurement in marine coastal sediments? Aquat. Sci. 55, 19-30. doi: 10.1007/bf00877256

Qiu, Y., Wang, Z., and Zhu, L. (2005). Variation trend of nutrient and chlorophyll contents and their effects on ecological environment in Daya Bay. J. Oceanogr. Taiwan Str. 24, 132-139.

Roman, M. R., Ashton, K. A., and Gauzens, A. L. (1988). Day / night differences in the grazing impact of marine copepods. Hydrobiologia 168, 21-30. doi: 10.1007/978-94-009-3103-9_3

Saito, H., and Taguchi, S. (1996). Diel feeding behavior of neritic copepods during spring and fall blooms in Akkeshi Bay, eastern coast of Hokkaido. Jpn. Mar. Biol. 125, 97-107. doi: 10.1007/bf00350764

Shen, Z. L. (2001). Historical changes in nutrient structure and its influences on phytoplantkon composition in Jiaozhou Bay. Estuar. Coast. Shelf Sci. 52, 211-224. doi: 10.1006/ecss.2000.0736

Shoemaker, K. M., and Moisander, P. H. (2017). Seasonal variability in the copepod gut microbiome in the subtropical North Atlantic Ocean. Environ. Microbiol. 19, 3087-3097. doi: 10.1111/1462-2920.13780

Song, S., Wang, Z., Fu, Y., and Gu, Y. (2009). Research on phytoplankton community at micro-layer in Dapengao Area of Daya Bay. Mar. Environ. Sci. $28,181-185$.

Sopanen, S., Koski, M., Kuuppo, P., Uronen, P., Legrand, C., and Tamminen, T. (2006). Toxic haptophyte Prymnesium parvum affects grazing, survival, egestion and egg production of the calanoid copepods Eurytemora affinis and Acartia bifilosa. Mar. Ecol. Prog. Ser. 327, 223-232. doi: 10.3354/meps327223

Sullivan, B. K. (1993). How doest water column structure influence copepod populations in coastal marine systems? Bull. Mar. Sci. 53, 240-246.

Sun, C.-C., Wang, Y.-S., Wu, M.-L., Dong, J.-D., Wang, Y.-T., Sun, F.-L., et al. (2011). Seasonal variation of water quality and phytoplankton response patterns in Daya Bay, China. Int. J. Environ. Res. Public Health 8, 2951-2966. doi: 10.3390/ijerph8072951

Tan, Y., Huang, L., Chen, Q., and Huang, X. (2004). Seasonal variation in zooplankton composition and grazing impact on phytoplankton standing stock in the Pearl River Estuary, China. Cont. Shelf Res. 24, 1949-1968. doi: 10.1016/ j.csr.2004.06.018

Tang, K. W., Chen, Q. C., and Wong, C. K. (1994). Diel vertical migration and gut pigment rhythm of Paracalanus parvus, $P$. crassirostris, Acartia erythaea and Eucalanus subcrassus (Copepoda, Calanoida) in Tolo Harbour, Hong Kong. Hydrobiologia 292-293, 389-396. doi: 10.1007/bf00229964

Tipton, K., and Bell, S. S. (1988). Foraging patterns of two syngnathid fishes: importance of harpacticoid copepods. Mar. Ecol. Prog. Ser. 47, 31-43. doi: 10.3354/meps047031

Tiselius, P. (1988). Effects of diurnal feeding rhythms, species composition and vertical migration on the grazing impact of calanoid copepods in the Skagerrak and Kattegat. Ophelia 28, 215-230. doi: 10.1080/00785326.1988.1043 0814

Tseng, L.-C., Dahms, H.-U., Chen, Q.-C., and Hwang, J.-S. (2009). Copepod feeding study in the upper layer of the tropical South China Sea. Helgol Mar. Res. 63, 327-337. doi: 10.1007/s10152-009-0162-y

Turner, J. T. (2004). The Importance of small planktonic copepods and their roles in pelagic marine food webs. Zool. Stud. 43, 255-266.

Wang, H., Hong, H., and Xu, L. (1999). Separation and determination of chlorophylls and caroenoids from marine phytoplankton by RP-HPLC. Mar. Sci. 124, 6-9.

Wang, L., Ou, L., Huang, K., Chai, C., Wang, Z., Wang, X., et al. (2018). Determination of the spatial and temporal variability of phytoplankton community structure in Daya Bay via HPLC-Chemtax pigment analysis. Chin. J. Oceanol. Limnol. 36, 1-11.

Wang, R., Zhang, H. -Y., Wang, K., and Zuo, T. (2002). Function performed by small copepods in marine ecosystem. Oceanol. Limnol. Sin. 33, 453-460.

Wang, X. H., Du, F. Y., and Qiu, Y. S. (2010). Variations of fish species diversity, faunal assemblage, and abundances in Daya Bay in 1980-2007. Chin. J. Appl. Ecol. 21, 2403-2410.

Watkins, J. M., Rudstam, L. G., and Holeck, K. T. (2011). Length-Weight Regressions for Zooplankton Biomass Calculations - A Review and a Suggestion for Standard Equations. Available online at: http://hdl.handle.net/1813/24566 (accessed October 1, 2020).

Wei, G. F. (2003). Responses of Phytoplankton to Nutrient Structure Changes in Daya Bay. Ph. D thesis. Guangzhou: South China Sea Institute of Oceanology.

Weisse, T., Tande, K., Verity, P., Hansen, F., and Gieskes, W. (1994). The trophic significance of Phaeocystis blooms. J. Mar. Syst. 5, 67-79. doi: 10.1016/09247963(94)90017-5

Williams, R., Conway, D. V. P., and Hunt, H. G. (1994). The role of copepods in the planktonic ecosystems of mixed and stratified waters of the European shelf seas. Hydrobiol. 292, 521-530. doi: 10.1007/BF00229980

Wlodarzyk, E., Durbin, A. G., and Durbin, E. G. (1992). Effect of temperature on low feeding thresholds, gut evacuation rate, and diel feeding behavior in the copepod Acartia hudsonica. Mar. Ecol. Prog. Ser. 85, 93-106. doi: 10.3354/ meps085093

Wu, C., Chiang, K.-P., and Liu, H. (2010). Diel feeding pattern and prey selection of mesozooplankton on microplankton community. J. Exp. Mar. Biol. Ecol. 390, 134-142. doi: 10.1016/j.jembe.2010.05.003

Wu, C. J., Shin, C. M., and Chiang, K. P. (2011). Does the mesh size of the plankton net affect the result of statistical analyses of the relationship between the copepod community and water masses? Crustaceana 84, 1069-1083. doi: 10.1163/001121611x586701

Wu, M.-L., Wang, Y.-S., Wang, Y.-T., Yin, J.-P., Dong, J.-D., Jiang, Z.-Y., et al. (2017). Scenarios of nutrient alterations and responses of phytoplankton in a changing Daya Bay, South China Sea. J Mar. Syst. 165, 1-12. doi: 10.1016/j. jmarsys.2016.09.004

Wu, M. -L., Wang, Y. -S., Wang, Y. -T., Sun, F. -L., Sun, C.-C., Cheng, H., et al. (2016). Seasonal and spatial variations of water quality and trophic status in Daya Bay, South China Sea. Mar. Pollut. Bull. 112, 341-348. doi: 10.1016/j. marpolbul.2016.07.042

Wu, M. -L., Wang, Y. -T., Cheng, H., Sun, F., Fei, J., Sun, C., et al. (2020). Phytoplankton community, structure, and succession delineated by partial least square regression in Daya Bay, South China Sea. Ecotoxicology 29, 751-761. doi: 10.1007/s10646-020-02188-2

Zapata, M., Rodrígues, F., and Garrido, J. L. (2000). Separation of chlorophylls and carotenoids from marine phytoplankton: a new HPLC method using a reversed 
phase C8 column and pyridine-containing mobile phases. Mar. Ecol. Prog. Ser. 195, 29-45. doi: 10.3354/meps195029

Zervoudaki, S., Christou, E. D., Nielsen, T. G., Siokou-Frangou, I., Assimakopoulou, G., Giannakourou, A., et al. (2007). The importance of small-sized copepods in a frontal area of the Aegean Sea. J. Plankton Res. 29, 317-338. doi: 10.1093/plankt/fbm018

Zhang, K., Guo, J., Xu, Y., Jiang, Y., Fan, J., Xu, S., et al. (2020). Long-term variations in fish community structure under multiple stressors in a semiclosed marine ecosystem in the South China Sea. Sci. Total Environ. 745:140892. doi: 10.1016/j.scitotenv.2020.140892
Conflict of Interest: The authors declare that the research was conducted in the absence of any commercial or financial relationships that could be construed as a potential conflict of interest.

Copyright (C) $2021 \mathrm{He}$, Wang, Bai, Han and Chen. This is an open-access article distributed under the terms of the Creative Commons Attribution License (CC BY). The use, distribution or reproduction in other forums is permitted, provided the original author(s) and the copyright owner(s) are credited and that the original publication in this journal is cited, in accordance with accepted academic practice. No use, distribution or reproduction is permitted which does not comply with these terms. 